\title{
Guillaine Barre Syndrome after OPCAB Surgery
}

\author{
Murali Vettath, A. V. Kannan \\ Malabar Institute of Medical Sciences, Kozhikode, India \\ Email: mvettathcts@hotmail.com
}

Received 21 September 2014; revised 20 October 2014; accepted 15 November 2014

Academic Editor: Bulang Gao, Shanghai Jiao Tong University, China

Copyright (C) 2014 by authors and Scientific Research Publishing Inc.

This work is licensed under the Creative Commons Attribution International License (CC BY).

http://creativecommons.org/licenses/by/4.0/

(c) (i) Open Access

\begin{abstract}
We report a successful treatment of the first reported case of Guillaine-Barre Syndrome (GBS) detected post Off Pump Coronary Artery Bypass Surgery (OPCAB). A 70-year-old man underwent OPCAB surgery for Triple Vessel Disease. In the post-operative period he developed respiratory distress with unexplained weakness in the limbs. CSF study confirmed Guillaine-Barre Syndrome. He was administered immunoglobulin therapy. The patient fully recovered and was discharged in good health.
\end{abstract}

Keywords

GBS, OPCAB, Immunoglobulin

\section{Introduction}

Guillaine-Barre Syndrome (GBS), also known as acute inflammatory demyelinating polyneuropathy and Landry's Ascending Paralysis is often preceded by an infection that is believed to evoke an immune response. Cross reaction with peripheral nerve components because of shared epitopes results in polyneuropathy [1]. Many reports have documented the occurrence of GBS after events such as immunization, surgery and trauma. There are reports of GBS following cardiac surgery using cardiopulmonary bypass [2] [3]. We present below the first case of GBS after Off Pump Coronary Artery Bypass (OPCAB) surgery reported in literature.

\section{Case Report}

A 70-year-old man was admitted with a history of anterior wall Myocardial Infarction. He had been thrombolysed from a local hospital two weeks ago. The patient had no history of diabetes mellitus or hypertension. He 
had an existing left side facial palsy and post-polio paralysis of right lower limb. Coronary Angiogram carried out revealed Triple Vessel Disease. He was referred here for Coronary Artery Bypass Surgery.

He underwent OPCAB with 2 grafts and was shifted to cardiac surgical ICU (CSICU). He was haemodynamically stable during and after the procedure and on the 3rd post-operative day (POD) was shifted to the room. He developed atrial fibrillation with fast ventricular rate, which as managed with Amiodarone infusion. He developed respiratory distress with unexplained weakness on the left side on the 7th POD in the room. The patient was shifted to CSICU and ventilated for 1 day. On the 8th POD he was given a trial extubation but was again reintubated as he desaturated due to lack of respiratory effort. He was then referred to the Neurologist. Neurological examination showed quadriparesis with more weakness in distal muscles than proximal muscles and areflexia. CT Scan of Brain was within normal limits. CSF study showed albumino-cytological dissociation with raised proteins without any cells suggestive of the Guillaine-Barre Syndrome. The patient was given intravenous immunoglobulin (IV Ig) at $20 \mathrm{~g} /$ day for 6 days.

Tracheostomy was done on post-operative day 15th. His muscle power gradually improved and he was weaned off the ventilator on the 31st POD. He developed episodes of sepsis which was treated with appropriate antibiotics. He improved with aggressive physiotherapy and was able to stand with support and lift both hands. Tracheostomy was removed and he was discharged home on 44th POD He was advised to continue vigorous physiotherapy. The patient presented himself after one year at our outpatients in extremely good health. He is now able to walk and drive the car independently.

\section{Discussion}

GBS is currently considered to be one of the commonest causes of acute generalized flaccid paralysis. Onset is sudden with nerve inflammation leading to rapidly progressive muscle weakness, with greatest weakness in the first two weeks and by the 3rd week $90 \%$ of the patients are at their weakest. It is reported that some have residual weakness even after 3 years. GBS has remained a descriptive disorder with no specific diagnostic test. A spinal tap and a nerve conduction velocity (NCV) test can aid diagnosis. The actual cause is not known but respiratory or gastro-intestinal infection can cause GBS. In some cases surgery and vaccination have triggered the syndrome. Cases of GBS following coronary artery bypass surgery done with cardiopulmonary bypass have been reported [2] [3]. Hence, this is the first reported case of GBS after OPCAB. In these cases patients developed weakness, require mechanical ventilation and plasmapheresis.

Immunoglobulin and plasma exchange (PE) treatment have shown muscle improvement in patients though the recovery phase is gradual. No difference was found between intravenous Immunoglobulin (Ig) and PE with respect to improvement in disability grade after 4 weeks, the duration of mechanical ventilation, mortality and residual disability [4]. The patient in this case report was treated with IV Ig at a dose of $20 \mathrm{~g} /$ day for 6 days. The patient successfully recovered GBS following off pump coronary artery bypass surgery.

\section{References}

[1] Van Doorn, P.A., Ruts, L. and Jacob, B.C. (2008) Clinical Features, Pathogenesis and Treatment of Guillain-Barre Syndrome. The Lancet Neurology, 7, 939-950.

[2] Renlund, D.G., Hanley, D.F. and Trail, T.A. (1987) Guillain-Barre Syndrome Following Coronary Artery Bypass Surgery. American Heart Journal, 113, 844-845. http://dx.doi.org/10.1016/0002-8703(87)90736-8

[3] Hogan, J.C., Briggs, T.P. and Oldershaw, P.J. (1992) Guillain-Barre Following Cardiopulmonary Bypass. International Journal of Cardiology, 35, 427-428. http://dx.doi.org/10.1016/0167-5273(92)90248-2

[4] Mukherji, S., Aloka, F., Farooq, M.U., Kassab, M.Y. and Abela, G.S. (2009) Cardiovascular Complications of the Guillain-Barre. The American Journal of Cardiology, 104, 1452-1455. 
Scientific Research Publishing (SCIRP) is one of the largest Open Access journal publishers. It is currently publishing more than 200 open access, online, peer-reviewed journals covering a wide range of academic disciplines. SCIRP serves the worldwide academic communities and contributes to the progress and application of science with its publication.

Other selected journals from SCIRP are listed as below. Submit your manuscript to us via either submit@scirp.org or Online Submission Portal.
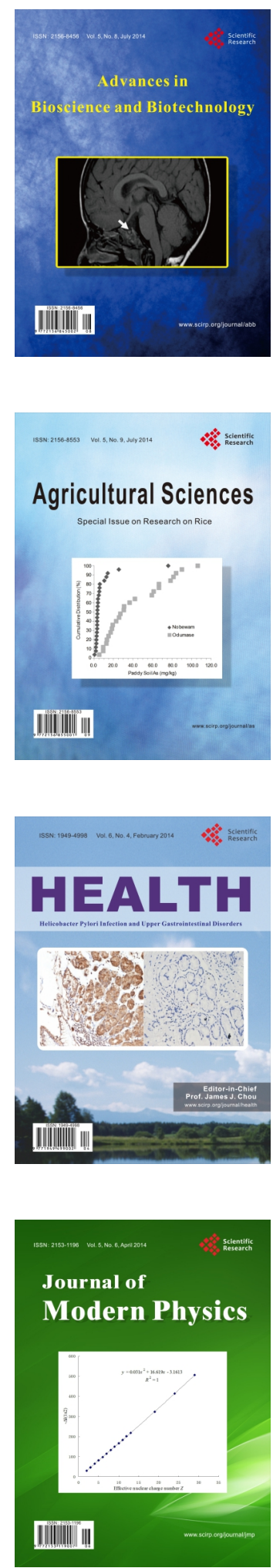
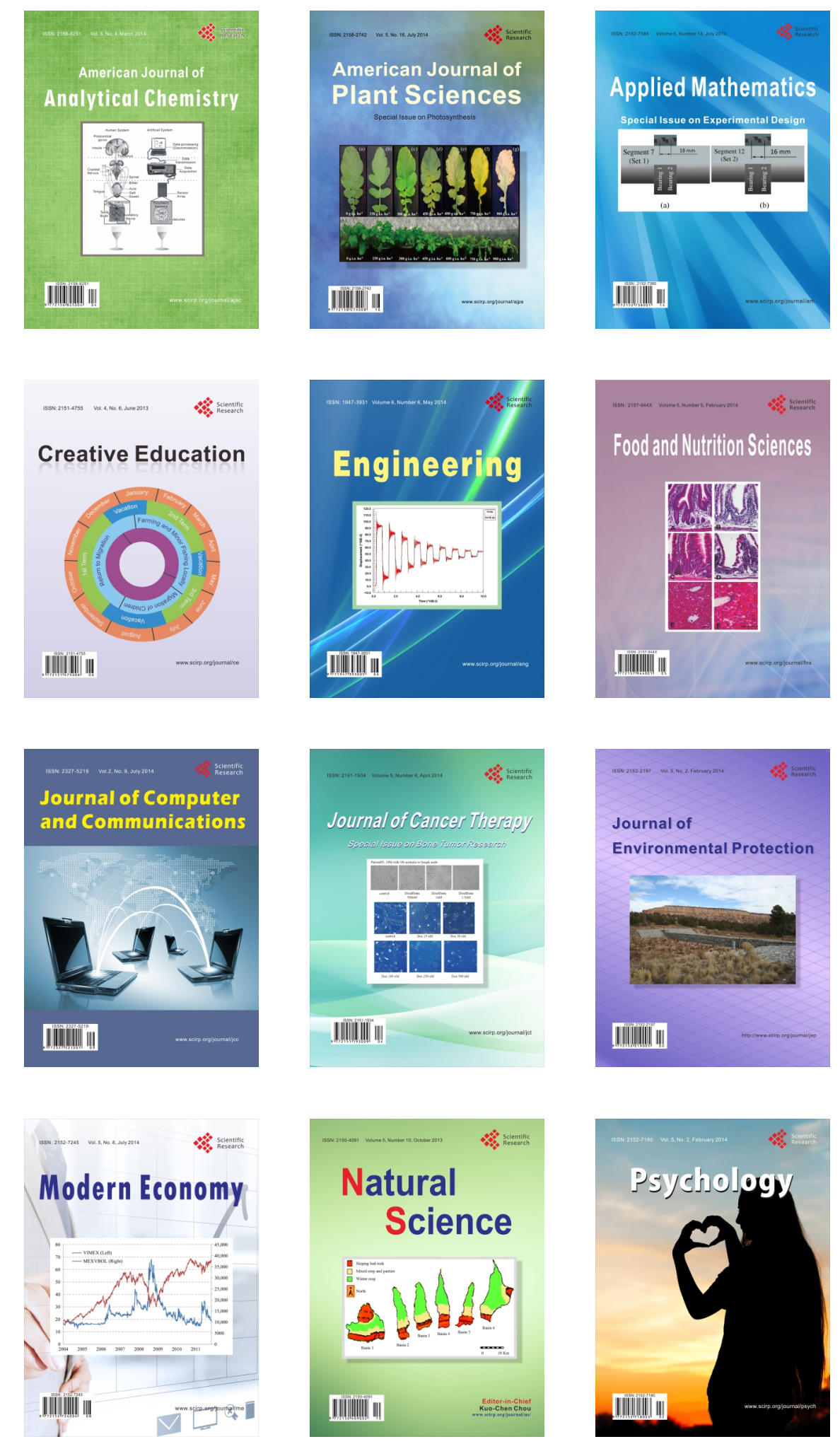